\title{
Prospects of using cordon-free bush technology in the commercial production of Black Satin variety blackberry
}

\author{
Vladimir Podorozhny* \\ Krymsk Experiment Breeding Station of VIR, N.I. Vavilov All-Russian Institute of Plant Genetic \\ Resources, Krymsk, Krasnodar Region, Russia
}

\begin{abstract}
As a result of the work, the commercial plantations' design elements of prostrate and semi-prostrate forms of garden blackberry (Eubatus Focke) were optimized. When constructing the agrocenosis of semi-prostrate blackberry forms according to the cordon-free bush technology, it is proposed to place the planting material in a single-line planting with a distance of at least one meter between plants on one meter wide rows covered with black polymer film with a tube laid under it for drip irrigation and fertigation. The growing annual shoots are recommended to be shortened to a height of $80-90 \mathrm{~cm}$, and the newly formed shoots of the second and subsequent orders - pinched at 30-40 cm height. As a result of these operations, fruit buds are laid on shortened shoots for the next year, which does not require their fastening to the cordon. According to the field experiments in the cordon-free bush Black Satin variety plantings, the output of commercial products for the research years increased more than twice as that from a unit of area at the supportcordon placement.
\end{abstract}

\section{Introduction}

Blackberry (Eubatus Focke) is one of the most valuable berry crops, the fruits of which have unique healing and dietary properties for the human body. According to our data [1], depending on the variety in the growing conditions of the North Caucasus foothill zone of the Russian Federation, they contain up to $7 \%$ of sugars, among which easily digestible fructose and glucose prevail, up to $1.5 \%$ of free acids, up to $26 \mathrm{mg} \%$ of ascorbic acid, over $19 \mathrm{mg} \%$ vitamin $\mathrm{P}$, etc. Garden blackberry is an early-maturing high-yielding crop; consequently, breeding work on obtaining new varieties is actively carried out and its cultivation area in the world is significantly increased [2-8]; with this, semi-prostrate and prostrate forms are mainly used for cultivation. This is explained by the fact that there are many thornless varieties among them, which are highly productive and have large berries of good quality [2].

In the world, the technology of commercial semi-prostrate and prostrate blackberries cordon-growing [9] is mainly used. Its modifications differ only in the shoot fixation

\footnotetext{
* Corresponding author: kross67@mail.ru
} 
method. The cordon consists of 7 feet high poles arranged in a row at a distance of 3 to 4 meters with tightly drawn 4 wire rows at 3, 4, 5 and 6 feet high. Plants are set out at a 2.4$3.6 \mathrm{~m}$ distance in a row and $2.7-3.0 \mathrm{~m}$ in the inter-row, while for successful fruiting the shoots must have a length of at least 2.6-3.6 m and fastened to the wire by different systems: "loop" provides for each plant's stem separation into two parts, then each part is separately lifted to the top wire, wrapped around it once or twice and let down to the lower wire with one or two turn around it as well, but in the opposite direction towards the bush; "rope" or "four-arm" system - each stem is fastened by tying or wrapping around a separate wire.

Disadvantages of this method are low planting density per hectare, labor intensity of all operations associated with fruiting shoots' tying, high cost of cordon and its installation.

Purpose of research - production intensification, productivity increase and rapid time to value of garden blackberries' commercial planting.

\section{Materials and methods}

Research was carried out in 2014-2016 at the Krymsk EBS, VIR Branch at the site of blackberries' variety study station. Plantation was laid in 2011 in the vicinity of the city of Krymsk located on the banks of the Adagum River in the foothills of the North-Western part of the Main Caucasus Range, $102 \mathrm{~km}$ southwest of the city of Krasnodar and $53 \mathrm{~km}$ northeast of the city of Novorossiysk. The climate is moderately continental. The soils are loamy.

Objects of study:

- Black Satin variety of garden blackberry (catalog number VIR 14823A). It was bred in the US. Annual shoots reach $6 \mathrm{~m}$ long, they are thornless, semi-prostrate. Berries are large, black, shiny, egg-shaped, sweet and sour. Fruits ripening in the experimental conditions - from the second decade of July until the end of August. Winter resistance and drought resistance - medium. In accordance with the methodical recommendations existing in VIR [10], it was selected at the primary variety study from the collection of the Crimean EBS VIR branch.

- commercial plantations of two types: support-cordon and cordon-free bush laid on one site. Each planting had 100 single-line plants.

The first (control) planting was equipped with a cordon consisting of reinforced concrete poles 2.1 meters high arranged at $4.0 \mathrm{~m}$ row distance, with a tight wire drawn in four rows at heights of $0.9 ; 1.2 ; 1.5 ; 1.9 \mathrm{~m}$. Plants were placed at a distance of $3.0 \mathrm{~m}$ in a row and $3.0 \mathrm{~m}$ in an inter-row, while the growing shoots were not cut and fastened to the wire by the "loop" system.

In the second planting, plants were set out in rows pre-mulched with black polymer film resistant to photodegradation and high solar insolation, $1 \mathrm{~m}$ wide, with a tube laid under it for drip irrigation and fertigation. The film edges were dusted with earth. The seedlings were set out in prepared holes in mulching film of $10 \mathrm{~cm}$ diameter at a distance of $1.0 \mathrm{~m}$ in a row, the dropper was located above the root system. The row width from edge to edge of the film was $1.0 \mathrm{~m}$. Annual shoots were trimmed during the growing season at $80-90 \mathrm{~cm}$ height. The shoots of the second and next orders formed from them as regrowth were pinched at a height of $30-40 \mathrm{~cm}$.

In both options, shoots with finished fruiting were trimmed at soil level and removed from the plantation. Six fruiting shoots were left on the accounting plant. The maintenance work in the plantings consisted of inter-rows' rotary tillage at both sites and a row in the control option.

Basic records and observations in planting were carried out in accordance with the "Program and Methods of Variety Study of Fruit, Berry and Nut Crops" [11]. 
In field experiments:

- biological features of phenological phases' passage of blackberries' seasonal growth and development were observed;

- the following traits were studied: number of peduncles, number of berries, average, minimum and maximum berry weight, total and commercial harvest.

The number of commercial berries or commercial productivity was determined by the final number of berries selected in accordance with GOST 3525-75. The percentage of crop losses was calculated as the difference between total and commercial yield per site. The average berry weight was estimated by dividing the commercial yield by the number of commercial berries.

The quantitative evaluation of the experimental results was performed using dispersion analysis [12]. Mathematical processing of the obtained data was carried out using the computer program Excel and Statistics 10.

\section{Results and discussion}

The intensification of the garden plants' production process provides for maximum use of the area under planting and, accordingly, compacted plantings. The optimal density of Black Satin variety plants in the cordon-free bush planting was determined by us in the course of previous studies [13]. Plants in the experimental planting were well developed and not oppressed (Figure 1).

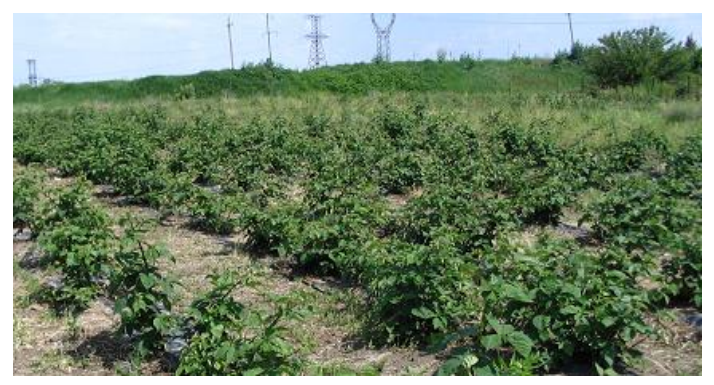

Fig. 1. Cordon-free bush planting of blackberry variety Black Satin, Krymsk EBS, VIR Branch, 2013

In case of further practical use of the studied method of conducting blackberry agrocenosis in production, it is necessary to vary the planting density considering the soil and climatic conditions of the cultivation zone, as well as varietal features of the specific blackberry form taken for cultivation. In this case, important factors are the structure and area of the plant's root system, the bush habitus after trim and the degree of its foliage.

Biological features' studies of growth and development of the Black Satin blackberry variety plant's above-ground part grown on cordon without shoots shortening showed that when the average daily average air temperatures decrease and daylight shortens by the beginning of autumn, fruit buds were formed on such shoots from the middle and to the apical part in the leaf axils. The laying of flower formations took place in these buds, from which the fruits were formed the following year.

When growing the studied variety according to the cordon-free bush technology, with growing annual shoots cutting at a height of $80-90 \mathrm{~cm}$ and further shortening of the second and subsequent orders' shoots formation, the fruit buds laying for the next year took place directly on shortened shoots and the plant flowered abundantly in the subsequent vegetation year (Figure 2). 


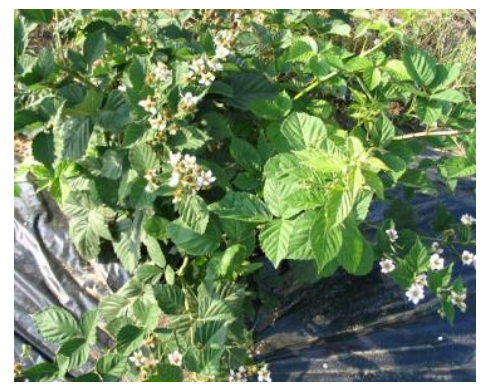

Fig. 2. Black Satin blackberry flowering with shortened trim Krymsk EBS, VIR Branch, 2014

Thus, the implementation of this technological operation caused the transfer of the fruiting zone on the shoot from the apical and middle part to the basal part

Due to favorable weather and climatic conditions of the study years, the variety taken as an observation object in our experiments did not require shelter for the winter. But it can be assumed that growing in more northern regions with severe climatic conditions with required winter shelter [14] can give additional advantages when grown by the cordon-free bush type compared to the support-cordon type. In such a planting, shoots removal from the cordon is not required in the technological process.

The main production efficiency indicator in evaluating the commercial planting in our experiments was its commercial productivity and yield. The bush formed according to the cordon-free bush type gave a full harvest (Figure 3).

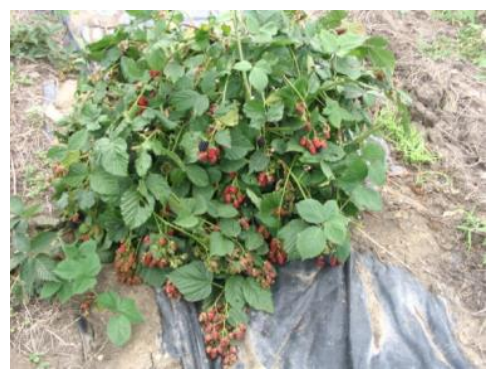

Fig. 3. Fruiting Black Satin variety blackberries formed by the bush type, Krymsk EBS, VIR Branch, 2015

Analyzing its first component — productivity gained during the years of study, we noted significant differences on this indicator in experimental options (table 1).

Table 1. Commercial productivity and yield of Black Satin blackberry variety depending on the planting type, Krymsk EBS, VIR Branch, 2014-2016

\begin{tabular}{|c|c|c|c|c|c|c|c|c|}
\hline \multirow{2}{*}{ Planting type } & \multicolumn{4}{|c|}{ Bush productivity, kg } & \multicolumn{4}{c|}{ Yield, $\mathrm{t} / \mathrm{ha}$} \\
\cline { 2 - 10 } & 2014 & 2015 & 2016 & $\overline{\mathrm{x}}$ & 2014 & 2015 & 2016 & $\overline{\mathrm{x}}$ \\
\hline Support-cordon (c) & 9.5 & 10.9 & 8.9 & 9.8 & 10.5 & 12.0 & 9.8 & 10.8 \\
\hline Cordon-free bush & 4.3 & 5.2 & 4.1 & 4.5 & 21.5 & 26.0 & 20.7 & 22.5 \\
\hline LCD $_{0.5}$ & 2.9 & 3.2 & 2.5 & 3.1 & 9.1 & 10.4 & 8.9 & 9.2 \\
\hline
\end{tabular}

The average commercial productivity for three years of variety study in the cordon-free bush planting amounted to $4.5 \mathrm{~kg}$, and on the support-cordon - $9.8 \mathrm{~kg}$. However, in recalculation per hectare, the yield in the first option due to a thickened planting (5000 pcs./ha) was more than twice as high as the control planting (1100 pc./ha).

In our experiments, the planting type has no significant impact on the commercial harvest of blackberry fruit. At the same time, there was a great influence of adverse weather conditions of a particular research year during the growing season (high air temperatures, 
droughts, etc.) on the increase in the number of deformed and underdeveloped berries in the total harvest of both plantings in approximately equal numbers.

Analyzing the number of large fruits weighing more than $6.0 \mathrm{~g}$ in the blackberries harvest when cultivated in the studied plantations, their significant decrease in the experimental option compared to the control was noted, which can be attributed to a disadvantage of cordon-free bush technology. However, the main commercial quality indicator of blackberry - the average weight in both plantings - was slightly different (5.5 and $5.1 \mathrm{~g}$, respectively) and they corresponded to GOST, which, in turn, had no negative impact on the cost of the final product sold - fresh blackberry fruit.

Economic analysis of the blackberry fruits production efficiency on the cordon-free bush type was carried out using requirements cards presented by the economic department of the Krymsk EBS, VIR branch with a recalculation of the material costs per hectare and product prices in 2014; it showed that such technology is effective and environmentally justified starting from the first year of the planting's commercial fruiting ( table 2).

Table 2. Economic efficiency of Black Satin blackberry variety cultivation in different types of plantations, 2014, Krymsk EBS, VIR Branch

\begin{tabular}{|l|c|c|c|c|c|}
\hline $\begin{array}{c}\text { Planting } \\
\text { type }\end{array}$ & $\begin{array}{c}\text { Establishment } \\
\text { and operation } \\
\text { costs }\end{array}$ & $\begin{array}{c}\text { Yield, } \\
\mathrm{t} / \mathrm{ha}\end{array}$ & $\begin{array}{c}\text { Sales price, } \\
\text { thousand } \\
\text { rub./t }\end{array}$ & $\begin{array}{c}\text { Revenues from } \\
\text { sale, thousand } \\
\text { rub./ha }\end{array}$ & $\begin{array}{c}\text { Net profit, } \\
\text { thousand } \\
\text { rub./ha }\end{array}$ \\
\hline $\begin{array}{l}\text { Support- } \\
\text { cordon (c) }\end{array}$ & 1976 & 10.5 & 120 & 1250 & -716 \\
\hline $\begin{array}{l}\text { Cordon- } \\
\text { free bush }\end{array}$ & 1843 & 21.5 & 120 & 2580 & +737 \\
\hline
\end{tabular}

In the subsequent plantations use, the cost of the final product is significantly reduced due to the distribution of the principal costs amount incurred for the establishment for the following years, and the yield remains high (table 1) providing good profitability and costeffectiveness in semi-prostrate blackberry Black Satin varieties commercial production on the cordon-free bush technology.

\section{Conclusions}

As a result of the work, the design elements of commercial plantations of Black Satin blackberry varieties have been optimized.

For production plantings of semi-prostrate blackberry forms, it is recommended to use cordon-free bush cultivation technology, which allows to quickly recoup plantings' investments.

\section{Acknowledgement}

The work was performed on the VIR Collections of Plant Genetic Resources within the framework of the state task according to the thematic VIR plan on the project No. 06622019-0004 "Collections of vegetatively propagated crops (potatoes, fruit, berry, ornamental, grapes) and their wild relatives VIR — Study and Rational Use".

\section{References}

1. T.G. Prichko, I.A. Machneva, V.N. Podorozhny, T.V. Pechenkina, Criteria of precision of horticulture and viticulture technologies, 244 (2007)

2. I.V. Kazakov, Raspberry. Blackberry, 256 (2001) 
3. B.C. Strik, C.E. Finn, J.R. Clark, P. Banados, Acta Hortic., 777, 209 (2008)

4. J.R. Clark, C.E. Finn, Fruit, Vegetable and Cereal Science and Biotechnology, 5(1), 27 (2011)

5. C.E. Finn, B.C. Strik (2014) https://catalog.extension.oregonstate.edu/

6. C.E. Finn, J.R. Clark, Chronica Horticulturae, 51(3), 13 (2011)

7. B.C. Strik, C.E. Finn, Acta Hortic., 946, 56 (2012) http://www.actahort.org

8. S.N. Evdokimenko, V.L. Kulagina, Horticulture and viticulture, 4, 20 (2015)

9. D.G. Hessayon, Transworld publishers LTD 61-63 Uxbridge Road, 72 (1995)

10. A.A. Yushev, A.A. Sorokin, O.A. Tikhonova, S.Yu. Orlova, E.N. Kislin, O.E. Radchenko, N.Ya. Pupkova, A.V. Shlyavas, Collection of genetic resources of fruit and berry plants: conservation, replenishment, study, VIR, 87 (2016)

11. E.N. Sedov, T.P. Ogoltsova et al, Program and Methods of Variety Study of Fruit, Berry and Nut Crops, 606 (1999)

12. B.A. Dospekhov, Field experiment methodology, 351 (1985)

13. V.N. Podorozhny, Proceedings of applied botanical genetics and breeding, 180(2), 7 (2019)

14. L.A. Gruner, O.V. Kuleshova, Modern horticulture, 2(22), 1 (2017) 